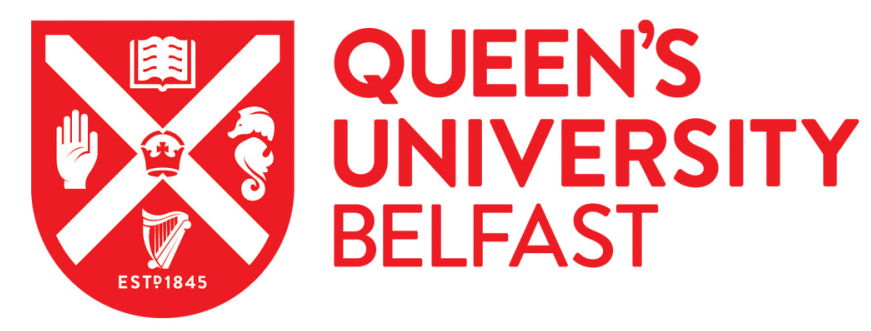

\title{
Interorganizational Collaborations for Humanitarian Aid: An Analysis of Partnership, Community, and Single Organization Outcomes
}

Nolte, I. M. (2018). Interorganizational Collaborations for Humanitarian Aid: An Analysis of Partnership, Community, and Single Organization Outcomes. Public Performance \& Management Review. https://doi.org/10.1080/15309576.2018.1462212

Published in:

Public Performance \& Management Review

Document Version:

Peer reviewed version

Queen's University Belfast - Research Portal:

Link to publication record in Queen's University Belfast Research Portal

Publisher rights

( ) 2018 Taylor and Francis. This work is made available online in accordance with the publisher's policies. Please refer to any applicable terms of use of the publisher.

\section{General rights}

Copyright for the publications made accessible via the Queen's University Belfast Research Portal is retained by the author(s) and / or other copyright owners and it is a condition of accessing these publications that users recognise and abide by the legal requirements associated with these rights.

Take down policy

The Research Portal is Queen's institutional repository that provides access to Queen's research output. Every effort has been made to ensure that content in the Research Portal does not infringe any person's rights, or applicable UK laws. If you discover content in the Research Portal that you believe breaches copyright or violates any law, please contact openaccess@qub.ac.uk. 


\title{
Inter-Organizational Collaborations for Humanitarian Aid: An Analysis of Partnership, Community, and Single Organization Outcomes
}

\author{
Dr. Isabella M. Nolte \\ Queen's University Belfast \\ Queen's Management School \\ i.nolte@qub.ac.uk
}

\begin{abstract}
This article explores collaborative activities across organizational and sectoral boundaries. Inter-organizational collaborations are an increasingly common setup to address societal needs, however, current research lacks insights into such collaborations and their outcomes. This study contributes to the existing literature by assessing empirically perceptions of interorganizational collaboration outcomes, considering different dimensions that should be measured when planning and performing tasks of social interest. The article is set in the context of disaster relief, where actors from different humanitarian relief organizations within the public and nonprofit sector engage in collaborative activities. We describe how interorganizational collaborations create outcomes for 1) the partnership structure that is established, 2) single organizational members involved in the collaborative activity, and 3) the community targeted by the inter-organizational operation.
\end{abstract}


Organizations from different sectors increasingly engage in joint projects, sharing tangible and intangible resources to reach public purposes (Gazley, 2008; Herranz, 2010; Mendel \& Brudney, 2012). Such inter-organizational collaborations are highly visible is the case of aid provision in developing regions, where inter- and supranational public and nonprofit organizations collaborate to provide aid. These collaborations often also involve local organizations, government, and the civil society, both targeting chronic issues like poverty or education, as well as acute issues like environmental or economic crises (Mukherjee Reed \& Reed, 2009). Recent years have shown a constant increase in resources directed towards aid projects in developing regions (Addison, Mavrotas, \& McGillivray, 2005) and Official Development Assistance (ODA) has reached more than USD 143 billion in 2016 (Organisation for Economic Co-operation and Development [OECD], 2017). From a public management perspective, it is crucial to ensure that these sums are used in the most efficient way, highlighting the importance of performance management within inter-organizational collaborations.

While public and nonprofit scholars have addressed issues like organizational performance on a single organization level for decades (Bagnoli \& Megali, 2011; Fry, 1984; Newton, 1973), the increase in collaborations also brought about a raised interest in the assessment and evaluation of public and nonprofit organizations engaging in inter-organizational collaborations (Bawole \& Hossain, 2015; Gazley, 2008; Gazley \& Brudney, 2007; Kenis \& Provan, 2009). However, while there are a number of anecdotal works addressing the management of inter-organizational collaborations (e.g. Cigler, 2007; Lund-Thomsen, 2009), studies on the topic of inter-organizational collaboration and their performance in an empirical setting remain scarce (Kelman, Hong, \& Turbitt, 2013; Ulibarri, 2015; Varda \& Retrum, 2015). Existing empirical studies focus on input-related factors (Gazley, 2008; Heide \& John, 1992), a consideration of multiple levels of outcomes to evaluate performance is 
missing. As Ulibarri (2015, p. 580) states: "Outcomes are the least-studied aspect of collaborative governance".

In this study, we address this research gap and change from an input- to an outcome-oriented perspective by looking at humanitarian relief organizations engaged in disaster response activities. Disasters create situations that require extensive collaboration, presuming that public services can be delivered more effectively in collaboration than in a single organizational setup (Kapucu, 2009; O’Leary, Gazley, McGuire, \& Blomgren Bingham, 2009). This study contributes to the literature on inter-organizational collaborations by pursuing two research goals: First, different dimensions of collaborative outputs and outcomes relevant for the disaster context will be identified, and second, effects of collaborative activities on three different outcome levels: the single organization, partnership, and community level, will be assessed empirically.

The study proceeds by laying out a research framework derived from the literature. The research setting, the case of the 2010 Haiti earthquake response, is then introduced. The analysis and results are presented and discussed in the following parts. The study concludes with implications for research and practice.

\section{RESEARCH FRAMEWORK AND LITERATURE}

In an organizational setting, the term collaboration is used to describe relationships between organizations that reflect high levels of interaction (Cigler, 2001). Collaboration is a more embedded form of engaging in joint activities than communication, cooperation, or coordination: Goals are more closely aligned and resources are shared more extensively (Keast, Brown, \& Mandell, 2007; Martin, Nolte, \& Vitolo, 2016). In their study on different forms of integration meanings and strategies, Keast, Brown, and Mandell (2007) find that 
"Collaboration was perceived as a more intensive process than the preceding integration forms [cooperation and coordination] and one that required much closer relationships, connections and resources".

Resource dependence theory helps to explain the creation of inter-organizational collaborations: Organizations work together to exchange resources and knowledge, as no single organization can be completely self-sufficient (Pfeffer \& Salancik, 1978; Varda \& Retrum, 2015). In the disaster context, tangible resources can be money, vehicles, mobile laboratories, or other equipment that is lent or shared. Knowledge is a main intangible asset shared within the disaster response. No single organization has the complete overview and information of what is happening and where aid is needed the most. Thus, organizations depend on each other to stay informed and make decisions.

Organizations engaged in humanitarian relief are endowed with different resources and can often only reach their organizational goals when working together with other organizations with complementing resources, experiencing resource interdependence (Clarke \& Fuller, 2010; Saidel, 1991). Smaller nonprofit organizations may be dependent on funds provided by donor organizations, such as United Nations agencies or larger INGOs, while organizations working on the strategic base may depend on operational knowledge of organizations active on the ground (Ebrahim, 2002; Khieng \& Dahles, 2015).

\section{Collaborative value creation}

Organizations working together combine resources that can be considered collaboration inputs, such as material or human resources, and conduct activities, before they achieve any results. While the immediate products and services that are delivered in a collaborative setting constitute collaboration outputs, the mid- to long-term events or conditions that result 
from collaborative activities constitute collaboration outcomes (Koontz \& Thomas, 2012; van Dooren, de Caluwe, \& Lonti, 2012). Outputs relate to the efficiency of a collaborative disaster response, while outcomes address the adequacy and effectiveness with which organizations achieved the intended results, their created value. The relationship between outputs and outcomes is a cause-and-effect relationship, where the initial outputs of collaboration trigger certain outcomes (Lynch, Lenihan, \& Hart, 2009). Organizations engaging in collaborations are often dissatisfied with the actual outcomes achieved, facing challenges like conflicts and a lack of accountability of collaborative activities (Madhok \& Tallman, 1998; Varda \& Retrum, 2015).

\section{Collaborative outputs}

Existing studies that assess the outputs of inter-organizational collaborations often look at indicators relating to time and quality (Bryson, Crosby, \& Stone, 2006; Kemshall \& Ross, 2000; Li, Akintoye, Edwards, \& Hardcastle, 2005; Ulibarri, 2015). Previous research has shown that time is crucial for humanitarian relief, especially in the first-response phase to disasters (Cigler, 2007; Comfort, Ko, \& Zagorecki, 2004). Response actions have to be coordinated and carried out quickly, because peoples' lives and goods are at stake. Comfort et al. (2004, p. 296) state: "In the initial stages of disaster, immediate demands involve actions to protect lives and provide assistance to injured persons. First-response organizations such as fire departments, emergency medical services, and police departments seek to meet urgent demands of disaster victims under tight time constraints".

Quality is relevant when organizations provide critical services such as health care, security, sanitation or infrastructure in partnership with other organizations, and poor quality in any of these arenas negatively impacts assistance in the mid- to long-term response activities 
(Kemshall \& Ross, 2000). The concepts of time and quality may be interdependent, as a very quick provision of services may lead to a decrease in quality and vice-versa. We use indicators relating to timeliness and quality of a disaster response to measure collaboration outputs, as shown in the research framework in Figure 1.

[Figure 1 here]

\section{Collaborative outcomes}

According to Provan and Milward (2001), three dimensions to evaluate collaborative outcomes exist and will be distinguished in this study: partnership, community, and single organization outcomes. Collaborative outputs are connected to each of these three outcome dimensions in the research framework and will be explained further in the following paragraphs.

\section{Partnership outcomes}

When evaluating the outcomes of a collaborative disaster response, one outcome is for the partnership itself. For example, more agencies might be attracted to a well-functioning collaboration, thus leading to an increase in partnership agreements (Lynch et al., 2009). In the phase after the immediate disaster response, collaborating organizations are better linked with each other, resulting in a stronger partnership that might lead to joint savings on combined projects, or integrations and synergies on joint grants, for example. Thus, partnership outcomes are directly linked to the outputs of inter-organizational collaborations. 
While the relationship between quality and outcomes has been tested in single-organizational, public and private settings before (Adjaoud, Zeghal, \& Andaleeb, 2007; Meier \& O’Toole, 2002), it remains unclear whether this relationship exists for the case of public service collaborations. Similarly, the timeliness of service provision is addressed in the existing literature and linked to outcomes in a number of studies focusing on the health sector (Kelman \& Friedman, 2009). However, it remains to be discussed how a timely response can affect outcomes of the partnership as a whole. We expect that both factors will have positive effects on partnership outcomes and derive the following hypotheses:

Hypothesis 1a: The timeliness of a collaborative disaster response is positively related to partnership outcomes.

Hypothesis 1b: The quality of a collaborative disaster response is positively related to partnership outcomes.

Community outcomes

A second dimension to be considered when studying inter-organizational collaborations is the effect of provided goods and services on beneficiaries of the disaster response. Through the collaborative disaster response, communities can acquire knowledge and capabilities that help protect them against possible future disasters (Whitman, 2009). Members of local communities and local organizations can learn from disaster responders about disaster response or recovery, for example the building of shelter or the prevention of diseases through sanitary measures (Whitman, 2009). Another possible community outcome might be a better capacity to respond to disasters due to the initial goods and services received from the professional disaster respondents, resulting in a strengthened community (Comfort, Sungu, 
Johnson, \& Dunn, 2001). Thus, community outcomes are directly linked to collaborative outputs in the research framework.

If goods and services for the disaster response can be provided quickly, the affected community can benefit from them right from the beginning, facilitating disaster relief. For example, communities can be involved in rescue operations and achieve learning effects once the basic necessities like housing, health, or nutrition are provided. A good quality of provided services can also have positive effects for the community, e.g. by providing better health services, future diseases can be prevented and communities can be more resilient to disasters. We derive the following hypotheses.

Hypothesis 2a: The timeliness of a collaborative disaster response is positively related to community outcomes.

Hypothesis $2 b$ : The quality of a collaborative disaster response is positively related to community outcomes.

Single organization outcomes

A third dimension that should be assessed when studying the effects of inter-organizational collaborations is the single member organization's outcome (Provan, Fish, \& Sydow, 2007; Provan \& Milward, 2001). Organizations involved in inter-organizational collaborations are autonomous actors that pursue joint goals during the collaboration but also act as individual organizations in other contexts (Romzek et al., 2014). The outputs that were achieved in a collaborative setting can affect management at the single organizational level. Learning, for example, is one outcome that results from a good response and affects the single organization level (Comfort, 1994; Provan et al., 2007). Additionally, an increased range of service 
capacity that was acquired due to the collaboration with other organizations during the disaster response can be an important single organization outcome (Babiak, 2009).

Single organizations that are part of a collaborative that achieved a timely disaster response may employ some of the mechanisms that led to the timely disaster response in their own, day-to-day operations. This can include capabilities to prioritize activities or to avoid bureaucratic hurdles that may slow down an emergency response. Learning within a single organization can also result from a high-quality response. If an organization experiences how members of their collaboration provide services of high quality that do not lead to problems in the long-run, e.g. providing medical aid and avoiding subsequent infections, this can be an incentive for single organizations to also focus on the provision of such high-quality services, as the cost of these services may ultimately be lower than services of poor quality that will need to be adjusted in the future. Therefore, if goods and services are delivered quickly and with good quality, single organizations can identify best practices and implement this knowledge for their own operations. We derive the following two hypotheses:

Hypothesis 3a: The timeliness of a collaborative disaster response is positively related to single organizational outcomes.

Hypothesis 3b: The quality of a collaborative disaster response is positively related to single organizational outcomes.

In addition to the effects that are triggered directly by collaborative outputs, we expect that single organizations can also benefit from the outcomes they achieved within the partnership. By partnering with other organizations, single organizations can employ best practices and learn themselves how to provide services more efficiently in the future (Babiak, 2009; Gazley \& Brudney, 2007). Different organizations that engage in disaster response collaborations 
share knowledge and organizations that have strengths in one area, such as the provision of drinking water, might learn from organizations that specialize in different areas, such as infrastructure, transportation, or security. Additionally, the legitimacy of a single organization involved in a collaboration may be enhanced by a good partnership performance through reputational effects (Provan \& Milward, 2001). Reputation and an organization's image are crucial in the disaster context, as public and nonprofit organizations are often dependent on funders and policy makers (Milward \& Provan, 1998).

Therefore, partnership outcomes are linked to single organization outcomes in the research framework. Single member organizations can benefit greatly from the knowledge, information, financial access, security and legitimacy of strong inter-organizational collaborations.

Partnership outcomes are also regarded as a mediator between the two types of partnership outputs and single organization outcomes. As stated earlier, changes in the timeliness and quality of a collaborative disaster response may lead to changes in partnership outcomes, for example to a larger, stronger network of responding organizations. We assume that this change in partnership outcomes in turn affects single organization outcomes. A larger network of organizations can create more opportunities for single organizations to exchange resources with other organizations, e.g. with regard to knowledge exchange. Thus, partnership outcomes are seen as a mechanism that links partnership outputs to single organization outcomes and the mediating role that partnership outcomes play for the relationship between collaborative outputs and single organization outcomes will be analysed.

Hypothesis 3c: The partnership outcomes of a collaborative disaster response are positively related to single organizational outcomes. 
Hypothesis 3d: The relationship between a timely collaborative disaster response and the experience of positive single organizational outcomes will be partially mediated by partnership outcomes.

Hypothesis 3e: The relationship between a disaster response of high quality and the experience of positive single organizational outcomes will be partially mediated by partnership outcomes.

The hypotheses above are connected in the research framework in Figure 1. While partnership and single organization outcomes address the organizational level, community outcomes address the level of beneficiaries. No links between outcomes on the organizational level and community outcomes are proposed in the framework, as outcomes experienced by the community cannot feed back into a single organization and outcomes experienced on the organizational level do not affect communities.

\section{STUDY CONTEXT: THE 2010 HAITI EARTHQUAKE}

The developed research framework is tested in the context of the response to the Haiti earthquake on January 12, 2010. Haiti is considered the poorest country in the Americas with vulnerabilities regarding systemic poverty, weak governance, and a high exposure to natural hazards (Inter-Agency Standing Committee [IASC], 2010). The country has been a recipient of ODA for decades and received more than 1 billion USD of ODA per annum since the 2010 earthquake (Muggah, 2010; OECD, 2016).

Humanitarian assistance after the Haiti earthquake was mainly provided through organizations engaging in inter-organizational collaborations (Patrick, 2011). For example, 
the public aid organization USAID partnered with INGO (international non-governmental organization) World Vision to distribute food commodities, while US military personnel provided logistical assistance (The White House, 2010). While nonprofit organizations were often involved in providing services to the community, public actors such as military, marine, and police were assisting with security and coordination. Several aid organizations such as the United Nations stabilization mission in Haiti (MINUSTAH) or the United Nations Office for the Coordination of Humanitarian Affairs (UN-OCHA) had already been present in Haiti at the time of the earthquake. However, these UN institutions, as well as the Haitian national government, were severely affected by the disaster, as UN headquarters, warehouses and government buildings were destroyed and in-country staff were among the victims of the earthquake (IASC, 2010; UN News Centre, 2010). Patrick (2011) states: "Specifically the National Disaster Risk Management System, Emergency Operations Centre and the Direction de la Protection Civile, Port au Prince's main fire station and innumerable government vehicles were badly damaged or destroyed".

As a result, there was a massive international community response to the Haiti earthquake (Patrick, 2011). Many arrived into the country, in addition to those already stationed there for humanitarian relief activities required from a number of tropical storms that had occurred in the months before the earthquake. By the end of January 2010, several hundred public and nonprofit organizations from all over the world were on-site and this number continued to grow for the following year (Patrick, 2011). With the highest number of NGOs per capita, Haiti is often referred to as 'the republic of NGOs' (Kristoff \& Paranelli, 2010; Muggah, 2010).

In the case of a large-scale disaster occurring in a developing region, the United Nations and specifically UN-OCHA usually take the leadership role to coordinate the disaster response (Kent, 2004). The so-called UN Cluster System was developed to centralize and coordinate 
disaster response activities. Organizations join different clusters, depending on the disaster response activities they provide, like education, food, water, sanitation and hygiene, or health. This mechanism was immediately applied in Haiti, where most large international organizations engaged in collaborative activities that were coordinated by the UN. Parallel forms of partnership organization such as the coordination of German organizations by the German embassy in Port-au-Prince or the joint activities of pre-established alliances also existed.

\section{RESEARCH METHOD}

A subset of data from a larger online-survey of respondents to the Haiti earthquake was used to test the research framework empirically. The survey had been pre-tested by a group of 24 Master students in Disaster Management Studies. 1,214 individuals working for more than 500 different organizations that attended UN cluster meetings in Haiti were invited to participate in the final survey. A total of 291 questionnaires or 24 percent of the surveys were returned. The survey was offered in English only, as English was the language spoken in the cluster meetings, and every individual participating in these meetings should have an understanding of the language. To further support the quantitative results from this study, we present these quantitative findings in line with a number of qualitative statements we received through interviewing seven aid managers involved in the Haiti earthquake response in autumn 2010. 


\section{Data and sample characteristics}

This analysis includes data from 208 managers that attended UN cluster meetings in Haiti, 83 cases were excluded because too many items were left unanswered, and remaining missing values were imputed using the EM algorithm (Dempster, Laird, \& Rubin, 1977). Survey respondents worked for organizations that acted in different fields of the disaster response: Camp coordination and management, education, emergency shelter and non-food items, food, logistics, protection, water, sanitation and hygiene, agriculture, early recovery, emergency telecommunications, and health.

Respondents worked for international and local public and nonprofit organizations, such as ACDI/VOCA Haiti, Habitat for Humanity International, International Committee of the Red Cross, Islamic Relief Worldwide, Scouts d'Haiti, Save the Children, Sri Lanka Army, and World Health Organization. Of the surveyed disaster respondents, the large majority, 71.2 percent, reported they worked for a nonprofit organization, 23.1 percent for a public organization. The remaining respondents either worked for a private organization or did not specify the sector they worked in. This distribution is in line with the distribution of organizations in our contact list, where slightly less than three quarter of the organizations were nonprofit organizations, one quarter public organizations and the remaining organization private organizations. With regard to organization size, 44.2 percent of the respondents stated that they worked for a large organization with more than 249 employees. 19.2 percent worked for a medium sized organization with 50 to 249 employees, 19.7 percent for a small organization with 11 to 49 employees. The remaining 16.8 percent of aid workers were active for a very small organization with 10 or less employees. Most surveyed persons held an executive position, either CEO/CFO, team leader or a non-specified executive position. Again, this reflects the composition of our contact list, where most people attending cluster meetings held an executive position. The organizations participating in cluster 
meetings were primarily larger organizations. This structure was confirmed by one of our interviewees, who explained that smaller organizations often lacked the human resources to participate in cluster meetings.

Due to the constant influx of NGOs during the time of the earthquake response and due to the resulting complexity, there are no official statistics on the composition of aid during the Haiti earthquake response. At the time of the earthquake response, Haiti ranked 175 on the 182 scale of the corruption perceptions index and the lack of transparency and accountability of aid was highly criticized (Center for Economic and Policy Research [CEPR], 2013; Transparency International, 2011). When we compare the final sample to our contact lists and the information on the composition of aid taken from existing reports, this sample seems to underline the fact that those organizations that responded under the structure of the UN cluster mechanism were largely international and rather large nonprofit organizations (Kristoff \& Paranelli, 2010). Table 1 gives a summary of the sample characteristics.

[Table 1 here]

\section{Conceptualization and measurement}

The conceptualization of the factors used in the research framework is based on a review of the literature, followed by in-depth interviews with disaster management experts. We chose a reflective specification of all factors and asked respondents to rate the variables on a sevenpoint Likert scale with items ranging from $1=$ strongly agree to $7=$ strongly disagree (for a formulation of the items, see Table 2). The reliability of the scales was tested using Cronbach's alpha (Nunnally, 1978). In addition, control variables for the size of organization 
and a dummy variable for type of organization (with $1=$ public organization, $0=$ other organization) were included.

[Table 2 here]

Regarding collaboration outputs, items to capture the quality and the timeliness of the collaborative activities were developed. Items to assess quality include aspects of the desired effectiveness of service provision, acceptance of provided services or products, consistency, and efficiency (Kemshall \& Ross, 2000). The construct of time is measured including indicators for a fast arrival and fast provision of services in the disaster region ( $\mathrm{Li}$ et al., 2005). Our reliability test indicates a high level of internal consistency of the scale with a Cronbach alpha value of 0.93 for quality and 0.80 for time.

Following the distinction by Provan and Milward (2001), outcomes were explored for three levels: 1) The network of aid organizations as a whole (partnership outcome), 2) people who are directly affected by a disaster and receive help of collaborating organizations (community outcome), and 3) each individual organization involved in the collaborative response as a single actor (single organization outcome).

Two variables are used to describe partnership outcome: network growth and relationship strength. To analyse the internal consistency of the scale, Cronbach's alpha is calculated. The alpha reliability for the two items measuring partnership outcome is 0.77 . The four items to measure community outcome include a strengthening and protection of the community, as well as the promotion of learning and social stability (Whitman, 2009). Cronbach's alpha for this scale is 0.88 . The items for single organization outcomes are based on previous research on inter-organizational collaborations. Knowledge acquisition is a vital outcome for single 
organizations after their engagement in collaborative disaster responses, as well as an improved effectiveness in addressing problems and an enhanced range of services provided (Babiak, 2009; Gazley \& Brudney, 2007). Based on institutional theory, an enhanced legitimacy of the organization in the eyes of other stakeholders is also included to assess organization outcomes (Babiak, 2009; DiMaggio \& Powell, 1983). The four items to measure organization outcome have a Cronbach alpha value of 0.80 .

\section{Analysis}

To test the hypothesized relationships statistically, we used structural equation modeling in AMOS. Descriptives and construct correlations are shown in Table 3. A couple of high correlations between the different constructs, particularly for the constructs time and quality, as well as partnership outcome and single organization outcome, can be seen and were expected. While these high correlations are unlikely to affect the stability of the model estimates (Mason \& Perreault, 1991), it is important to note that respondents experiencing a quick response also seemed to note a good quality, and that respondents perceiving positive partnership outcomes did tend to perceive positive single organization outcomes at the same time.

[Table 3 here]

Tests of multivariate normality show that the variables can be regarded approximately normal distributed. Therefore, the maximum likelihood method was applied to test whether the developed theoretical framework had a close fit to the data that was collected through the 
survey. We first conducted confirmatory factor analysis (CFA) to confirm the five-factor structure of the hypothesized model. A number of quality criteria were applied to assess the model fit of each tested model (Table 4). The five-factor solution had a better fit than a number of parsimonious models, including two four-factor solutions where time and quality (M2) or partnership outcomes and single organization outcomes (M3) were combined, as well as a two-factor model combining all output-related indicators into one latent variable for output and all outcome-related indicators into one single outcome variable (M4). The chisquared difference test was used to compare our models (Bentler \& Bonnett, 1980). Regarding fit indices, the Root Mean Square Error of Approximation (RMSEA) of the fivefactor model is below the threshold value of 0.08 , indicating a good model fit. The normed Chi Square ratio $\left(X^{2} / d f\right)$, showing how similar the model restricted covariance is to the sample covariance, is also acceptable with 1.70. We further used the fit indices Comparative Fit Index (CFI), Incremental Fit Index (IFI), Normed Fit Index (NFI) and Goodness-of-Fit-Index (GFI) to assess the model fit (Hu \& Bentler, 1999). All fit indices for the hypothesized model exceed the suggested value of 0.9 , thus the model fit proves satisfactory (Hair, Black, Babin, \& Anderson, 2010).

[Table 4 here]

After confirming the five-factor structure of our model, the hypothesized relationships within the research framework were tested in a structural model. Following the approach suggested by Hayes (2013), a mediation model including direct and indirect paths from partnership outputs to single organization outcomes was designed (see Figure 1). This originally theorized model was compared to two alternative models: A model where all three outcome 
dimensions were directly linked to both output factors and an alternative mediation model where outputs were only linked to single organization outcomes through partnership outcomes. The originally hypothesized mediation model showed good fit statistics $\left(X^{2} / d f=\right.$ $1.840, \mathrm{CFI}=0.953, \mathrm{IFI}=0.954 ; \mathrm{NFI}=0.904, \mathrm{GFI}=0.900, \mathrm{RMSEA}=0.064 ;$ ), while the alternative mediated model and the directly linked model violated some of the threshold criteria (alternative mediated model: $X^{2} / d f=1.906, \mathrm{CFI}=0.948, \mathrm{IFI}=0,949, \mathrm{NFI}=0,898$, $\mathrm{GFI}=0,894, \mathrm{RMSEA}=0.066$; directly linked model: $X^{2} / d f=2.525, \mathrm{CFI}=0.914, \mathrm{IFI}=$ $0,915, \mathrm{NFI}=0,867, \mathrm{GFI}=0,866, \mathrm{RMSEA}=0.086)$. Therefore, we rely on our originally theorized model and have a look at the standardized regression weights and $p$-values to make statements about the first to third set of hypotheses.

\section{RESULTS AND DISCUSSION}

The first set of hypotheses evolved around the topic of partnership outcomes. While a positive relationship between time and partnership outcomes was proposed in Hypothesis 1a, a positive relationship between quality and partnership outcomes was proposed in Hypothesis 1b. We do not find statistical support for Hypothesis 1a with a path coefficient of 0.055 ( $p>$ $0.05)$, while Hypothesis $1 \mathrm{~b}$ with a path coefficient of $0.487(p<0.001)$ is supported by the data. The second set of hypotheses focused on community outcomes. While Hypothesis 2a, suggesting a positive relationship between a timely response and community outcomes, could not be confirmed by the data $(\beta=-0.069, p>0.05)$, we found statistical support for Hypothesis $2 \mathrm{~b}$, showing that the quality of a disaster response does have a positive effect on outcomes experienced by the affected community $(\beta=0.587, p<0.001)$. Hypotheses $3 \mathrm{a}$ through e revolve around the dimension of single organizational outcomes. In line with the previous hypotheses, we proposed that both time (Hypothesis 3a) and quality (Hypothesis 3b) 
would positively affect single organization outcomes. Both hypotheses were not supported by the data.

We did find support for Hypothesis 3c, predicting that partnership outcomes are positively related to single organization outcomes, with a path coefficient of $0.793(p<0.001)$. As a significance of the direct effects is not a precondition for mediation analysis (Hayes, 2013), we proceed to calculate the indirect effects hypothesized in $3 \mathrm{~d}$ and $3 \mathrm{e}$. We took the product of each of the two path coefficients linking partnership outputs to single organization outcomes via partnership outcomes. The indirect effect of time on organizational outcomes over partnership outcomes was not significant with $0.044(p>0.05)$, while the effect of quality on organizational outcomes over partnership outcomes was significant with $0.386(p<0.001)$. The theorized model helps to explain $29 \%$ of the variance in partnership outcomes, $30 \%$ of the variance in community outcomes, and $79 \%$ of the variance in single organization outcomes. Standardized regression coefficients for the hypothesized model are shown in Table 5. The control variables yielded path coefficients below 0.1 and had no significant impact on the hypothesized relationships.

[Table 5 here]

To summarize, while the view that a high quality of service provision positively affects outcomes was supported for the context of partnership and community outcomes (Hypotheses $1 \mathrm{~b}$ and $2 \mathrm{~b}$ ), the relationship between a timely response and all three types of outcome dimensions (Hypotheses 1a, 2a, 3a) was not supported by the data. Quality and single organization outcomes were not positively related (Hypothesis $3 \mathrm{~b}$ ), however a positive direct relationship between partnership outcomes and single organization outcomes was found 
(Hypothesis 3c). The analysis also revealed that partnership outcomes act as a mediator between quality of service provision and single organization outcomes (Hypothesis 3e).

The significant positive effect of the quality of inter-organizational service provision on partnership outcomes is in line with findings from a single-organizational setting (Adjaoud et al., 2007; Meier \& O'Toole, 2002) and shows that the initial collaborative performance has an effect on the whole network of organizations involved in a disaster response. Good disaster performance can facilitate network growth, as more organizations might be attracted to a successful network. Existing members of the network that experienced a good partnership performance might also have higher incentives to maintain contact with other organizations. These results were also reflected in our interviews with practitioners. For example, one of our interviewees stated: “[our organization experienced] efficient partnership with local doctors and nurses, collaboration with American, Spanish, and Bulgarian medical teams, also improving of the collaboration with French disaster response services".

A significant positive effect was also found between quality of the inter-organizational response and community outcomes. In other words, a good initial disaster response can positively affect the development of the community, i.e. the provision of clean drinking water or shelter that is stable enough to resist bad weather conditions or future disasters may help strengthening the community against future threats. This result, in combination with the nonsignificant effect of timeliness of the response, leads to the suggestion that collaborations that may be indecisive between taking a bit more time in considering where and how to provide aid, as opposed to just delivering aid as quickly as possible, may be well-off by taking the time and measures to further improve the quality of their service provision. Of course, in some cases time is the only relevant factor, particularly in the first-response phase to a disaster where lives are threatened. Other services, such as the provision of drinking water, may well profit from a prioritization of quality over time. As one of our interviewees stated: 
In general, the water we distribute does have [...] drinking water quality. It has to have [this quality]. You cannot just throw a chlorine tablet into the water and hand out the water, which a lot [of collaboratives] do. Probably it is well-intentioned, in order to provide something at all, but this is the wrong way. Because by doing something that is actually wrong, you facilitate the spreading of diseases, you steer into the wrong direction.

Contrary to initial assumptions, the timeliness of a disaster response does not seem to affect collaborative outcomes. While time certainly plays a critical role during the initial disaster response (Cigler, 2007; Comfort, Ko, \& Zagorecki, 2004), it has no relevance for the creation of partnership outcomes, single organization outcomes, or community outcomes. A possible explanation for the non-significant effect on partnership outcomes may lie in our conceptualization of partnership outcomes. Both indicators - network growth and stronger relationships - address topics that usually improve over time. It therefore is likely that a timely initial disaster response is less relevant for these specific indicators and even the opposite may be true, that partnerships need to have time to strengthen their ties, which then facilitates the further development of the partnership (Provan \& Milward, 2001).

Our initial assumption, that a quick provision of the services most needed by the community can free resources, which then can be used for activities increasing resilience, does not hold true. As a consequence, we think that in order to enhance resilience, it is not necessarily important to provide services and goods as quickly as possible. Other factors, such as the involvement of the local community, may be factors that can have a greater effect on community outcomes and should be considered in the future (Ahmed, Abdulai, Osumanu, \& Salia, 2016; Shrestha, 2013). For the third outcome dimension, single organization outcomes, neither a significant relationship with the timeliness of a collaborative disaster response, nor with the quality of the response could be found. We assume that the pure fact that an organization is working together with other organizations does lead to outcomes for the single organization, however, the efficiency of the collaboration does not directly influence 
the degree to which single organizations can profit from collaboration. Organizations experiencing problems with other organizations or committing errors may as well take learnings from this experience, a response does not have to be perfect for a single organization to benefit.

The results further reveal that single organizations can experience positive effects resulting from the partnership and that the quality of a response ultimately does affect single organizations through these partnership outcomes. Thus, the importance of collaboration to achieve organizational outcomes in a disaster response is underlined. In general, there is no central control mechanism that makes participation in networks during disaster response obligatory. Organizations can choose whether to act autonomously or in a network. The analysis of organizational outcomes revealed that collaborating successfully can yield positive results for the single member organization. Pursuing joint goals in a collaborative setting provides organizations with the opportunity to gain insights into the partner's way of working and enables the acquisition of scarce resources, such as expert knowledge (Rathi, Given, \& Forcier, 2014). For example:

Our organization grew in its understanding of the organizational emotional impact of disaster response as something common to many nonprofits, wherein the organization actor desires to do something tangible and do it quickly, even if it is not the most appropriate response. By sharing corporate experiences with our collaborative partners, we educated each other in managing this dynamic better in the future.

Well performing partnerships can also gain the attention of politicians and funders, and organizations might be able to acquire resources more easily if they participated in a well performing disaster response. Finally, organizations that work together with others during disaster response can focus on the tasks they conduct best and address shared problems more efficiently. Concerning organizational outcomes, one respondent noted, reflecting on the collaborative: "We could do more with less resources, we could do better what we used to do". 


\section{CONCLUSION}

The case and findings presented above have important theoretical implications. First, this study contributes to the literature on collaborative activities in a disaster context. Given the increasing economic impact of natural and man-made disasters worldwide (Guha-Sapir et al., 2016), future research needs to address collaborative performance in crisis settings, helping to enhance the accountability of organizations engaged in joint service provision (Varda \& Retrum, 2015). Second, this study responds to calls for an empirical analysis of collaborative outcomes (Kelman, Hong, \& Turbitt, 2013; Ulibarri, 2015; Varda \& Retrum, 2015). It builds on literature that regards indicators to measure collaborative or public performance at a single output or outcome stage (Bagnoli \& Megali, 2011; Gazley, 2008) and adds findings relating to linkages between the two stages. Many studies elaborating on collaboration outputs and outcomes that look at the context of public service provision take a purely conceptual or qualitative angle and therefore cannot provide such insights (Babiak, 2009; Bryson et al., 2006).

This study addresses two major research goals that are of theoretical and practical relevance. First, it identifies collaborative outputs and outcomes across three important levels of the disaster response: the single organization, partnership, and community level. Second, it explores the relationship between these collaborative outputs and outcomes empirically. With respect to collaborative outputs, a main insight relates to the importance of quality. We add to the discussion on quality in public service collaborations (Kemshall \& Ross, 2000; Pishchikova, 2014) and find that quality, rather than timeliness, is what impacts on collaborative outcomes. Those collaborations that provide goods and services of better quality seem to be the ones that can create further outcomes. To enhance this effect, quality criteria should be defined for the joint delivery of products and services. Organizations can make agreements or create alliances and define jointly accepted quality criteria and common 
measures to improve the quality of public service provision. Measures can include regular meetings following a previously agreed agenda, shared feedback on progress throughout the project(s), and learning from each organization's experience through the development and publication of joint evaluation reports (Behn, 2010; Kenis \& Provan, 2009).

Another main finding of this study relates to the positive relationship measured between partnership outcomes and single organization outcomes. While the intrinsic motivation of disaster managers to provide aid is certainly high, public and nonprofit-organizations are organizations that cannot act in a purely altruistic way. Thus, organizations will be interested in the benefits a collaboration can have for their own, single organization. Apart from tangible resources, such as funds, intangible resources like legitimacy and operational knowledge can be acquired (Ebrahim, 2002; Saidel, 1991; Shrestha, 2013). When deciding whether to engage in collaborative activities or not, it is therefore important to consider the possible - often intangible - benefits of collaboration, rather than just counting the costs that incur when entering a collaboration and bringing in own resources.

This study has a number of limitations that give opportunities for further research. In this study, members of aid organizations evaluated all three types of outcomes, and local community members were not involved in the survey. Using community estimates to evaluate the external dimension, namely the community's evaluation of the interorganizational collaboration, is considered problematic in this context, in that community members' judgments might be based on a partial view of a collaboration's services (James, 2009). Few locals would have been able to appreciate the collaborations that took place behind the scenes and would have little basis on which to make comparisons. For the future, cases with larger degrees of involvement of the local community should be assessed and community members' opinions should be included to assess outcomes, particularly community outcomes. 
All studies looking into social behavior and relying on self-reported measures are prone to common method bias and this study is no exception. A number of measures were taken to reduce the effect of common method bias (Podsakoff, MacKenzie, Lee, \& Podsakoff, 2003). In addition to the interpretation of survey results, interview results were added to interpret and underline this study's findings. These interview results are a further source of information that helps to strengthen the findings from the online survey. Additionally, and in line with suggestions from Podsakoff et al. (2003), respondents to the survey and the interviews were granted anonymity. Future studies that want to capture the voices of affected communities will need to be more exploratory in nature and employ a mixed-methodology approach to understand the opinions of members of the local community and then bring these opinions into a format that can be used for statistical analysis. The move towards more reporting and accountability within nonprofit organizations engaged in the field of development can also facilitate the collection of objective data on partnership outcomes in the future, helping to further reduce common method bias.

Finally, non-independence issues of the survey data may have impacted on the results of this study, as respondents were not clustered by organization. For the future, different types of collaborations should be evaluated to see if outcomes, particularly partnership outcomes, are linked to a certain composition of the partnership. Subsequent studies that evaluate collaborative outcomes should consider different types of organizational structures, e.g. partnerships without central command (Kenis \& Provan, 2009) or partnerships involving higher numbers of public organization or higher numbers of locally based organizations. This can ultimately help to provide recommendations for an optimal partnership structure in different disaster contexts. 


\section{REFERENCES}

Addison, T., Mavrotas, G., \& McGillivray, M. (2005). Aid, debt relief and new sources of finance for meeting the Millennium Development Goals. Journal of International Affairs, 58(2), 113-127.

Adjaoud, F., Zeghal, D., \& Andaleeb, S. (2007). The effect of board's quality on performance: A study of Canadian firms. Corporate Governance, 15(4), 623-635.

Ahmed, A., Abdulai, A.-R., Osumanu, I. K., \& Salia, R. A. (2016). The contribution of donor support programs to decentralized development: Learning from the district level in Ghana. International Journal of Public Administration, 39(11), 821-832.

Babiak, K. M. (2009). Criteria of effectiveness in multiple cross-sectoral interorganizational relationships. Evaluation and Program Planning, 32(1), 1-12.

Bagnoli, L., \& Megali, C. (2011). Measuring performance in social enterprises. Nonprofit and Voluntary Sector Quarterly, 40(1), 149-165.

Bawole, J. N., \& Hossain, F. (2015). Marriage of the unwilling? The paradox of local government and NGO relations in Ghana. Voluntas: International Journal of Voluntary and Nonprofit Organizations, 26(5), 2061-2083.

Behn, R. D. (2010). Collaborating for performance: Or can there exist such a thing as CollaborationStat? International Public Management Journal, 13(4), 429-470.

Bentler, P. M., \& Bonnett, D. G. (1980). Significance tests and goodness of fit in the analysis of covariances structures. Psychological Bulletin, 88(3), 588-606.

Bryson, J. M., Crosby, B. C., \& Middleton Stone, M. (2006). The design and implementation of cross-sector collaborations: Propositions from the literature. Public Administration Review, 66(s1), 44-55. 
Center for Economic and Policy Research. (2013). Breaking open the black box: Increasing aid transparency and accountability in Haiti. CEPR, Washington, D.C.

Cigler, B. A. (2001). Multi-organizational, multisector and multicommunity organizations: Setting the research agenda. In M. P. Mandell (Ed.), Getting results through collaboration: Networks and network structures for public policy and management (pp. 71-85). Westport, CT: Quorum Books.

Cigler, B. A. (2007). The "big questions" of Katrina and the 2005 great flood of New Orleans. Public Administration Review, 67(s1), 64-76.

Clarke, A. \& Fuller, M. (2010). Collaborative strategic management: Strategy formulation and implementation by multi-organizational cross-sector social partnerships. Journal of Business Ethics, 94, 85-101.

Comfort, L. K. (1994). Self-organization in complex systems. Journal of Public Administration Research and Theory, 4(3), 393-410.

Comfort, L. K., Ko, K., \& Zagorecki, A. (2004). Coordination in rapidly evolving disaster response systems: The role of information. American Behavioral Scientist, 48(3), 295313.

Comfort, L. K., Sungu, Y., Johnson, D., \& Dunn, M. (2001). Anticipation and resilience in dynamic environments. Journal of Contingencies and Crisis Management, 9(3), 144158.

Dempster, A. P., Laird, N. M., \& Rubin, D. B. (1977). Maximum likelihood from incomplete data via the EM algorithm. Journal of the Royal Statistical Society, 39(1), 1-38. 
DiMaggio, P. J., \& Powell, W. W. (1983). The iron cage revisited: Institutional isomorphism and collective rationality in organizational fields. American Sociology Review, 48(2), $147-160$.

Ebrahim, A. (2002). Information struggles: The role of information in the reproduction of NGO-funder relationships. Nonprofit and Voluntary Sector Quarterly, 31(1), 84-114.

Fry, G. K. (1984). The development of the Thatcher government's "grand strategy" for the civil service: A public policy perspective. Public Administration, 62(3), 322-335.

Gazley, B. (2008). Beyond the contract: The scope and nature of informal governmentnonprofit partnerships. Public Administration Review, 68(1), 141-154.

Gazley, B., \& Brudney, J. L. (2007). The purpose (and perils) of government-nonprofit partnership. Nonprofit and Voluntary Sector Quarterly, 36(3), 389-415.

Guha-Sapir, D., Hoyois, P., Wallemacq, P., \& Below, R. (2016). Annual Disaster Statistical Review 2016: The Numbers and Trends. Brussels: CRED.

Hair, J. F., Black, W. C., Babin, B. J., \& Anderson, R. E. (2010). Multivariate data analysis. Upper Saddle River, NJ: Prentice-Hall.

Hayes, A. F. (2013). Introduction to mediation, moderation, and conditional process analysis: A regression-based approach. New York, NY: Guilford Press.

Heide, J., \& John, G. (1992). Do norms matter in marketing relationships? Journal of Marketing, 56(2), 32-44.

Herranz, J. (2010). Network performance and coordination: A theoretical review and framework. Public Performance \& Management Review, 33(3), 311-341. 
Hu, L., \& Bentler, P. M. (1999). Cutoff criteria for fit indexes in covariance structure analysis: Conventional criteria versus new alternatives. Structural Equation Modeling, $6(1), 1-55$.

Inter-Agency Standing Committee. (2010). Response to the humanitarian crisis in HaitiFollowing the 12 January 2010 earthquake. 6-Month Report.

James, O. (2009). Evaluating the expectations disconfirmation and expectations anchoring approaches to citizen satisfaction with local services. Journal of Public Administration Research and Theory, 19(1), 107-123.

Kapucu, N. (2009). Public administrators and cross-sector governance in response to and recovery from disasters. Administration \& Society, 41(7), 910-914.

Keast, R., Brown, K., \& Mandell, M. (2007). Getting the right mix: Unpacking integration meanings and strategies. International Public Management Journal, 10(1), 9-33.

Kelman, S., Hong, S., \& Turbitt, I. (2013). Are there managerial practices associated with the outcomes of an interagency service delivery collaboration? Evidence from British crime and disorder reduction partnerships. Journal of Public Administration Research and Theory, 23(3), 609-630.

Kelman, S., \& Friedman, J. N. (2009). Performance improvement and performance dysfunction: An empirical examination of distortionary impacts of the emergency room wait-time target in the English National Health Service. Journal of Public Administration Research and Theory, 19(4), 917-946.

Kemshall, H., \& Ross, L. (2000). Partners in evaluation: Modelling quality in partnership projects. Social Policy and Administration, 34(5), 551-566. 
Kenis, P., \& Provan, K. G. (2009). Towards an exogenous theory of public network performance. Public Administration, 87(3), 440-456.

Kent, R. C. (2004). The United Nations' humanitarian pillar: Refocusing the UN's disaster and emergency roles and responsibilities. Disasters, 28(2), 216-233.

Khieng, S., \& Dahles, H. (2015). Resource dependence and effects of funding diversification strategies among NGOs in Cambodia. Voluntas: International Journal of Voluntary and Nonprofit Organizations, 26(4), 1412-1437.

Koontz, T. M., \& Thomas, C. W. (2012). Measuring the performance of public-private partnerships. Public Performance \& Management Review, 35(4), 769-786.

Kristoff, M., \& Panarelli, L. (2010). Haiti: a republic of NGOs? Peace Brief 23. 26 April. Washington, DC: United States Institute of Peace.

Li, B., Akintoye, A., Edwards, P. J., \& Hardcastle, C. (2005). Perceptions of positive and negative factors influencing the attractiveness of PPP/PFI procurement for construction projects in the UK, Findings from a questionnaire survey. Engineering, Construction and Architectural Management, 12(2), 125-148.

Lund-Thomsen, P. (2009). Assessing the impact of public-private partnerships in the global south: The case of the Kasur Tanneries pollution control project. Journal of Business Ethics, 90(s1), 57-78.

Lynch, N., Lenihan, H., \& Hart, M. (2009). Developing a framework to evaluate business networks: the case of Ireland's industry-let network initiative. Policy Studies, 30(2): 163-180.

Madhok, A., \& Tallman, S. B. (1998). Resources, transactions and rents: Managing value through interfirm collaborative relationships. Organization Science, 9(3), 326-339. 
Martin, E., Nolte, I., \& Vitolo, E. (2016). The four Cs of disaster partnering: Communication, cooperation, coordination and collaboration. Disasters, 40(4), 621-643.

Mason, C. H., \& Perreault, W. D. Jr. (1991). Collinearity, power, and interpretation of multiple regression analysis. Journal of Marketing Research, 28(3), 268-280.

Meier, K. J., \& O’Toole, L. J. Jr. (2002). Public management and organizational performance: The effect of managerial quality. Journal of Policy Analysis and Management, 21(4), 629-643.

Mendel, S. C., \& Brudney, J. L. (2012). Putting the NP in PPP. Public Performance \& Management Review, 35(4), 617-642.

Milward, H. B., \& Provan, K. G. (1998). Measuring network structure. Public Administration, 76(2), 387-407.

Muggah, R. (2010). The effects of stabilisation of humanitarian action in Haiti. Disasters, 34(s3), 444-463.

Mukherjee Reed, A., \& Reed, D. (2009). Partnerships for development: Four models of business involvement. Journal of Business Ethics, 90(s1), 3-37.

Newton, M. (1973). Organizational development and changes organization climate. Public Personnel Management, 2(2), 84-92.

Nunnally, J. C. (1978). Psychometric theory. New York, NY: McGraw-Hill.

Organisation for Economic Co-operation and Development. (2016). Aid at a glance charts. Paris: OECD. http://www.oecd.org/countries/haiti/aid-at-a-glance.htm.

Organisation for Economic Co-operation and Development. (2017). Official development assistance 2016 - ODA 1960-16 trends. Paris: OECD. http://www2.compareyourcountry.org/oda? $\mathrm{cr}=20001 \& \mathrm{cr} 1=\mathrm{oecd} \& 1 \mathrm{~g}=\mathrm{en} \&$ page $=1$. 
O’Leary, R., Gazley, B., McGuire, M., \& Blomgren Bingham, L. (2009). Public managers in collaboration. In R. O’Leary \& L. Blomgren Bingham (Eds.), The Collaborative Public Manager (pp. 1-18). Washington, DC: Georgetown University Press.

Patrick, J. (2011). Haiti Earthquake Response: Emerging Evaluation Lessons. Evaluation Insights, Department for International Development, No. 1, June 2011.

Pfeffer, J., \& Salancik, G. R. (1978). The external control of organizations: A resource dependence perspective. New York, NY: Harper and Row.

Pishchikova, K. (2014). Greater synergy and improved collaboration: Do complex partnerships deliver on the promise in countries emerging from armed conflict? Voluntas: International Journal of Voluntary and Nonprofit Organizations, 25(1), 2-27.

Podsakoff, P. M., MacKenzie, S. B., Lee, J. Y., \& Podsakoff, N. (2003). Common method biases in behavioral research: A critical review of the literature and recommended remedies. Journal of Applied Psychology, 88(5), 879-903.

Provan, K. G., Fish, A, \& Sydow, J. (2007). Interorganizational networks at the network level: A review of the empirical literature on whole networks. Journal of Management, $33(3), 479-516$.

Provan, K. G., \& Milward, H. B. (2001). Do networks really work? A framework for evaluating public-sector organizational networks. Public Administration Review, 61(4), 414-423.

Rathi, D., Given, L. M, \& Forcier, E. (2014). Interorganisational partnerships and knowledge sharing: the perspective of non-profit organizations (NPOs). Journal of Knowledge Management, 18(5), 867-885. 
Romzek, B., LeRoux, K., Johnston, J., Kempf, R. J., \& Piatak, J. S. (2014). Informal accountability in multisector service delivery collaborations. Journal of Public Administration Research and Theory, 24(4), 813-842.

Saidel, J. R. (1991). Resource interdependence: The relationship between state agencies and nonprofit organizations. Public Administration Review, 51(6), 543-553.

Shrestha, M. K. (2013). Internal versus external social capital and the success of community initiatives: A case of self-organizing collaborative governance in Nepal. Public Administration Review, 73(1), 154-164.

The White House. Office of the Press Secretary. (2010). United States government Haiti earthquake disaster response update 1/21/10. Washington, DC: The While House.

Transparency International. (2011). Corruption Perceptions Index 2011. Berlin: Transparency International.

Ulibarri, N. (2015). Collaboration in federal hydropower licensing: Impacts on process, outputs, and outcomes. Public Performance \& Management Review, 38(4), 578-606.

UN News Centre (2010). Secretary-General Ban Ki-moon: Opening remarks at press conference in Port-au-Prince. New York, NY: UN News Centre.

Van Dooren, W., de Caluwe, C., \& Lonti, Z. (2012). How to measure public administration performance. Public Performance \& Management Review, 35(3), 489-508.

Varda, D. M., \& Retrum, J. H. (2015). Collaborative performance as a function of network members' perception of success. Public Performance \& Management Review, 38(4), $632-653$.

Whitman, J. R. (2009). Measuring social values in philanthropic foundations. Nonprofit Management and Leadership, 19(3), 305-325. 
FIGURE 1 Research framework

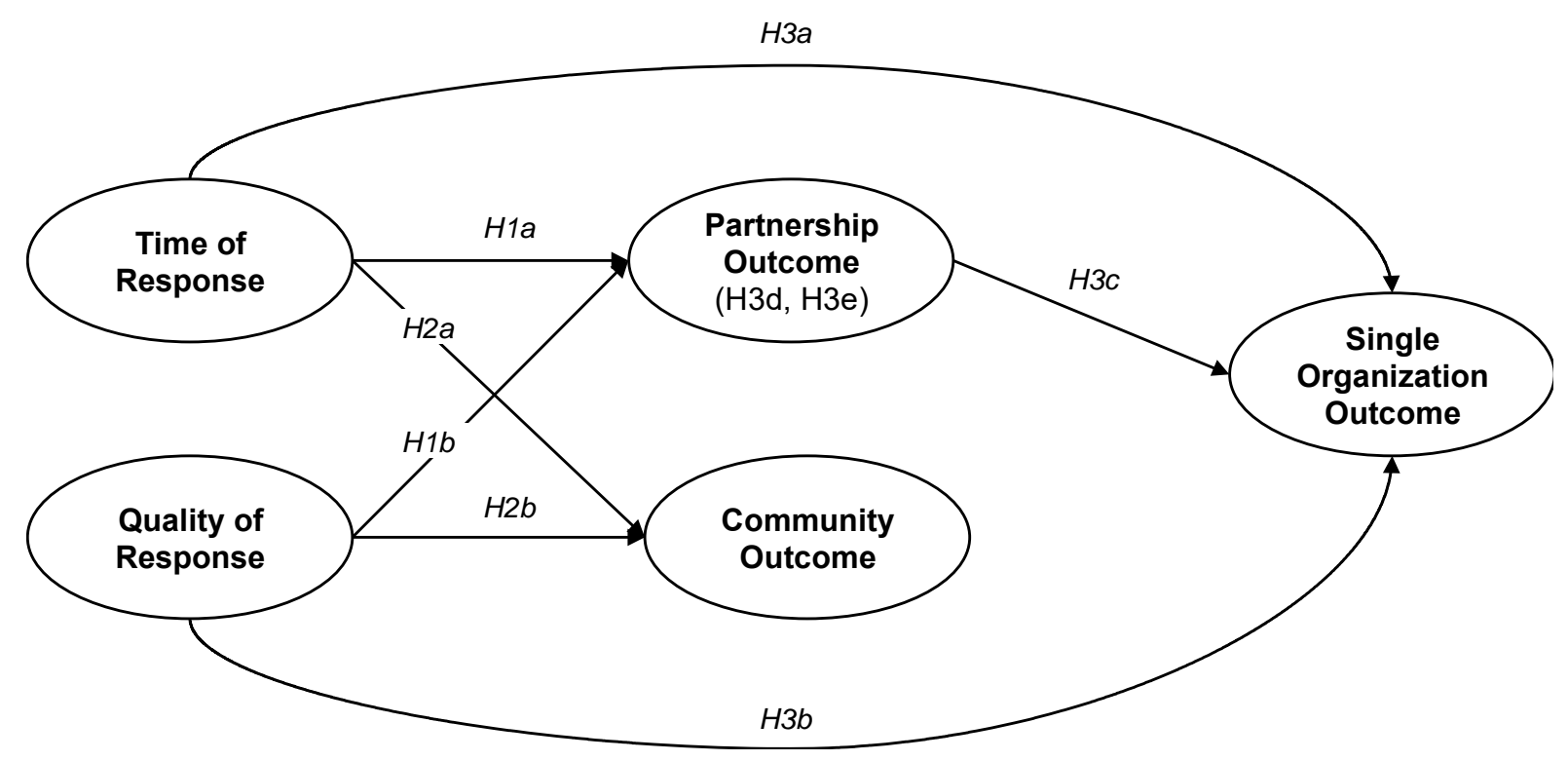




\section{TABLE 1 Sample characteristics}

\begin{tabular}{|c|c|c|c|}
\hline Variable & Specification & Valid percentage & $n$ \\
\hline \multirow{4}{*}{ Type of organization } & Nonprofit organization & 71.2 & 148 \\
\hline & Public organization & 23.1 & 48 \\
\hline & Private organization & 1.9 & 4 \\
\hline & Other & 3.8 & 8 \\
\hline \multirow{4}{*}{ Size of organization } & Large, $\geq 250$ employees & 44.2 & 92 \\
\hline & Medium, 50-249 employees & 19.2 & 40 \\
\hline & Small, 10-49 employees & 19.7 & 41 \\
\hline & Very small, $\leq 10$ employees & 16.8 & 35 \\
\hline \multirow{7}{*}{ Profession } & $\mathrm{CEO} /$ president & 9.1 & 18 \\
\hline & $\mathrm{CFO} /$ controller & 1.5 & 3 \\
\hline & Other executive/team leader & 66.7 & 132 \\
\hline & Non-manager & 3.5 & 7 \\
\hline & $\begin{array}{l}\text { Professional (e.g. nurse, } \\
\text { engineer) }\end{array}$ & 15.7 & 31 \\
\hline & Other & 3.5 & 7 \\
\hline & & Mean & \\
\hline $\begin{array}{l}\text { Existence of } \\
\text { organization }\end{array}$ & $\begin{array}{l}\text { Years of existence of the } \\
\text { organization }\end{array}$ & 38 & 202 \\
\hline Disaster experience & $\begin{array}{l}\text { Years the organization has been } \\
\text { involved in disaster } \\
\text { management activities }\end{array}$ & 26 & 201 \\
\hline
\end{tabular}


TABLE 2 Survey items

\begin{tabular}{|c|c|c|}
\hline Construct & Indicator & Statement \\
\hline \multirow[t]{2}{*}{ Time of response } & Fast Arrival & The collaboration with other organizations helped us to reach the disaster region fast. \\
\hline & Project Completion & The collaboration with other organizations helped us to complete our projects on-time. \\
\hline \multirow[t]{4}{*}{ Quality of response } & Desirability & $\begin{array}{l}\text { The collaboration with other organizations helped us to provide services or products that } \\
\text { had the desired effect. }\end{array}$ \\
\hline & Consistency & $\begin{array}{l}\text { The collaboration with other organizations helped us to provide services or products of the } \\
\text { same quality over time. }\end{array}$ \\
\hline & Acceptance & $\begin{array}{l}\text { The collaboration with other organizations helped us to provide services or products that } \\
\text { were accepted. }\end{array}$ \\
\hline & Efficiency & $\begin{array}{l}\text { The collaboration with other organizations helped us to provide services or products } \\
\text { efficiently. }\end{array}$ \\
\hline \multirow[t]{2}{*}{ Partnership outcome } & Growth & Our network of partnering organizations grew because of the disaster response. \\
\hline & Strong Relationship & The relationship to the organizations we collaborated with became stronger. \\
\hline \multirow{4}{*}{$\begin{array}{l}\text { Community } \\
\text { outcome }\end{array}$} & Strength & We strengthened the affected community by our collaborative activities. \\
\hline & Learning & We promoted learning by our collaborative activities. \\
\hline & Stability & We promoted social stability by our collaborative activities. \\
\hline & Protection & $\begin{array}{l}\text { We promoted the protection of the community from disaster by our collaborative } \\
\text { activities. }\end{array}$ \\
\hline \multirow[t]{4}{*}{$\begin{array}{l}\text { Single organization } \\
\text { outcome }\end{array}$} & Knowledge & $\begin{array}{l}\text { Our organization could generate new knowledge due to the collaboration with other } \\
\text { organizations. }\end{array}$ \\
\hline & Shared Problems & $\begin{array}{l}\text { Our organization could address shared problems more effectively due to the collaboration } \\
\text { with other organizations. }\end{array}$ \\
\hline & Service Range & The range of services we provided grew due to the collaboration with other organizations. \\
\hline & Legitimacy & $\begin{array}{l}\text { Our organization had an enhanced legitimacy in the eyes of the public, community, and } \\
\text { funders due to the collaboration with other organizations. }\end{array}$ \\
\hline
\end{tabular}


TABLE 3 Correlations and descriptive statistics

\begin{tabular}{|c|c|c|c|c|c|}
\hline & 1 & 2 & 3 & 4 & 5 \\
\hline 1. Time of response & - & & & & \\
\hline 2. Quality of response & $0.69 * *$ & - & & & \\
\hline 3. Partnership outcome & $0.37 * *$ & $0.42 * *$ & - & & \\
\hline 4. Community outcome & $0.37 * *$ & $0.49 * *$ & $0.44 * *$ & - & \\
\hline 5. Single organization outcome & $0.46^{* *}$ & $0.46^{* *}$ & $0.67 * *$ & $0.46 * *$ & - \\
\hline$M$ & 2.83 & 2.50 & 2.38 & 2.77 & 2.57 \\
\hline$S D$ & 1.48 & 1.21 & 1.28 & 1.23 & 1.14 \\
\hline Min-Max & $1-7$ & $1-7$ & $1-7$ & $1-7$ & $1-7$ \\
\hline
\end{tabular}

Means $(M)$ and standard deviations $(S D)$ are calculated from the means of the construct items.

**. Correlation is significant at the 0.01 level (2-tailed). 
TABLE 4 Fit indices of distinct measurement models

\begin{tabular}{|c|c|c|c|c|c|c|c|c|c|}
\hline Model fit & $x^{2}$ & $d f$ & $\Delta x^{2}$ & $\mathrm{X}^{2} / d f$ & CFI & IFI & NFI & GFI & RMSEA \\
\hline M1: five-factor model & 154.680 & 91 & - & 1.700 & 0.970 & 0.970 & 0.930 & 0.918 & 0.058 \\
\hline $\begin{array}{l}\text { M2: four-factor model } \\
\text { (time and quality combined) }\end{array}$ & 210.403 & 95 & $55.723^{\star \star \star}$ & 2.215 & 0.945 & 0.946 & 0.905 & 0.893 & 0.077 \\
\hline $\begin{array}{l}\text { (partnership outcome and } \\
\text { organization outcome } \\
\text { combined) }\end{array}$ & 165.549 & 95 & $10.869^{* * *}$ & 1.743 & 0.966 & 0.967 & 0.926 & 0.912 & 0.060 \\
\hline M4: two-factor model & 405.591 & 100 & $250.911^{* * *}$ & 4.056 & 0.783 & 0.856 & 0.818 & 0.783 & 0.122 \\
\hline
\end{tabular}




\section{TABLE 5 Standardized regression coefficients}

\begin{tabular}{llll}
\hline Hypothesis & \multicolumn{2}{c}{ Path } & $\begin{array}{c}\text { Standardized Path } \\
\text { Coefficient }\end{array}$ \\
\hline H1a & Time of response & $\rightarrow$ Partnership outcome & 0.055 \\
H1b & Quality of response & $\rightarrow$ Partnership outcome & $0.487^{* * *}$ \\
H2a & Time of response & $\rightarrow$ Community outcome & -0.069 \\
H2b & Quality of response & $\rightarrow$ Community outcome & $0.587^{* * *}$ \\
H3a & Time of response & $\rightarrow$ Single organization outcome & 0.140 \\
H3b & Quality of response & $\rightarrow$ Single organization outcome & 0.033 \\
H3c & Partnership outcome & $\rightarrow$ Single organization outcome & $0.793 * * *$ \\
H3d & Time $\rightarrow$ Partnership outcome & $\rightarrow$ Single organization outcome & 0.044 \\
H3e & Quality $\rightarrow$ Partnership outcome & $\rightarrow$ Single organization outcome & $0.386^{* * *}$ \\
\hline
\end{tabular}

Note: ${ }^{* * *}$ correlation is significant at the .001 level. 